\title{
Innovate with the CTI National Thematic Networks
}

\author{
Susanne Lauber Fürst*
}

\begin{abstract}
Winning in the global market place with brilliant innovations is the recipe for success for the Swiss economy. Indeed, Switzerland always stands out in the global rankings when it comes to innovation. Yet there is nothing as dangerous as to rest on one's laurels, and this is particularly true for R\&D-based businesses. For this reason CTI, the Commission for Technology and Innovation, offers Swiss companies quick and effective access to knowledge available at Swiss public research institutions, and to international R\&D programs promoting application-oriented research. Knowledge and technology transfer are promoted - via its KTT support - through National Thematic Networks (NTNs), Innovation Mentors and information platforms. The following article highlights the activities of the National Thematic Networks and invites Swiss companies and research institutes to benefit from the multiple offers and services available.
\end{abstract}

Keywords: CTI · KTT knowledge and technology transfer · National Thematic Networks

\section{What are National Thematic Networks?}

After a public tender, CTI has appointed eight NTN in a two-step selection process, which all started their activities in January 2013 (Table 1). Their role is to

Table 1. The eight National Thematic Networks (NTN)

In cooperation with the CTI

KTT-Support

National thematic networks

Schweizerische Eidgenossenschaft

Confédération suisse

Confederation suisse

Confederaziun svizra

Swiss Confederation

Commission for Technology and Innovation CTI be innovation engines for Switzerland by bringing together the private sector and public research institutes with the objective that ideas combined with competence lead to innovation. In this sense, NTN are bridge builders between those key innovation drivers. As a common trait, they:
- Focus on a specific innovation theme

- Have high relevance for the Swiss private and public sector

- Are active across Switzerland, in all language regions

\author{
Name and website \\ Carbon Composites Schweiz \\ www.cc-schweiz.ch \\ Inartis Network \\ www.inartis-network.ch \\ Innovative Surfaces \\ www.innovativesurfaces.ch
}

Swiss Biotech
www.swissbiotech.org

Swiss Food Research www.foodresearch.ch

Swiss Wood Innovation Network www.s-win.ch

Swissphotonics

www.swissphotonics.net

Association Network Logistics www.vln.ch

\section{Focus}

Promotes the application of high-performance fibre reinforced composites in Switzerland.

Increases the competitiveness of the Life Sciences sector with a transdisciplinary and cross-industry approach for 'Innovations Made in Switzerland'.

Is a leading network in Switzerland for targeted and performance-oriented Knowledge \& Technology Transfer (KTT) between public research institutions and companies seeking innovative surface technologies and collaborations to stimulate competitiveness and value creation.

Covers all relevant competences for Biotech across the entire value generation chain; from innovation through to product development and commercialization.

Promotes research and innovation across the agrofood chain and its related sectors to enhance the competitiveness of the Swiss agro \& food industry and its suppliers.

Provides a platform for innovative research on issues of the forest and wood-based value chain, including chemical and energetic use of wood.

Serves the full field of photonics to improve the competitiveness of its members through the support of the innovation forces.

Promotes the development and commercialization of innovative solutions in procurement, production, logistics and supply chain management. 


\section{How Do NTNs Operate?}

The NTNs' main mission is to enhance the dialogue between the research community of a very specific theme and the SMEs who could benefit from this technology. CTI requires that all NTNs are structured as non-for-profit organisations, governed by a Board representing industry and academia, professionally managed, and have a measurable impact all over Switzerland. All NTNs are therefore organised in a transparent way and are easily accessible. In short: There are no more excuses that companies think they have no time for innovation.

\section{Connecting Switzerland}

How often one can observe companies in the German speaking part of Switzerland preferring to look for $\mathrm{R} \& \mathrm{D}$ collaborations across the ocean rather than across the 'Röstigraben', and vice versa, of course. By building up their specific expertise, actively reaching out and offering their services to the innovation players in all regions of our country, NTNs play a critical role in connecting Switzerland within its borders.

Of course, Research and Development goes beyond our borders: NTNs' mandate includes helping Swiss companies and Swiss public research institutions to gain access to international $\mathrm{R} \& \mathrm{D}$ networks and knowhow available outside our small country. Connecting Switzerland - inside and outside - is of particular interest for SMEs to help boost their innovation capabilities. Competing in a globalised market-place requires excellence in all areas. For technologically specialised companies knowledge and technology transfer are even more relevant to stay innovative and competitive. Concretely, NTNs reach out to and actively establish international networks in their focus area to provide access to sources of innovation and new markets. Yet another good reason to get connected with the NTNs.

\section{How Can you Benefit from NTNs?}

NTNs offer smart linkage of private and public sector research to come up with innovation. The main services to foster knowledge and technology transfer all NTNs provide are fostering joint R\&D projects and organising events and workshops.

Market-oriented R\&D collaborations between Swiss businesses and public research institutes are of particular relevance. Next to CTI funded projects, NTNs also facilitate access to international $R \& D$ programs or to other forms of innovation collaborations. The NTNs' role varies with the complexity of the project and the needs of the project partners. As driving forces for their specific field of expertise, NTNs are certainly ideal specialists to scout for best in class partners, both on the public and the private sector side and be catalysts for supporting successful project applications.

All NTNs are proactively reaching out to the scientific and business community in their thematic field and are gladly supporting the innovation actors in the framework of their CTI performance mandate.

\section{INARTIS NETWORK - The Swiss Life Sciences community}

INARTIS NETWORK is the National Thematic Network focussing on the Life Sciences (Figs 1-3). Its mission is to create values and jobs across the Swiss Life Science economy through innovation 'Made in Switzerland'. As Federal Councillor Johann N. Schneider-Ammann underlined at the kick-off event at EPFL on 28 March 2013, "Without innovation, a national economy withers quickly, fades and then dies". The INARTIS NETWORK head office is situated in Renens/VD and is the only NTN from the Latin part of Switzerland; we therefore are particularly passionate to connect the Romandie with the Ticino and of course the Swiss German part. So called Innovation Consulates are our strategic bridgeheads situated in all parts of the country, with a recently opened Swiss German branch office in Zurich, which we operate in close collaboration with CSEM SA, Centre Suisse d'Electronique et de Microtechnique SA.

Bridge-building is important to overcome geographic barriers. Of equal importance is our role to build bridges between the scientific disciplines within the Life Sciences and between the different industry

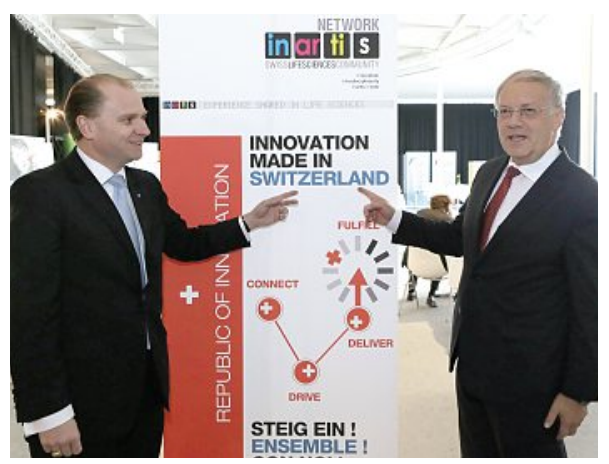

Fig. 1. Federal Council Johann N. SchneiderAmmann and Executive Council of canton Vaud Philippe Leuba standing together for 'Innovation Made in Switzerland' at the kick-off event of INARTIS NETWORK at EPFL on 28 March 2013

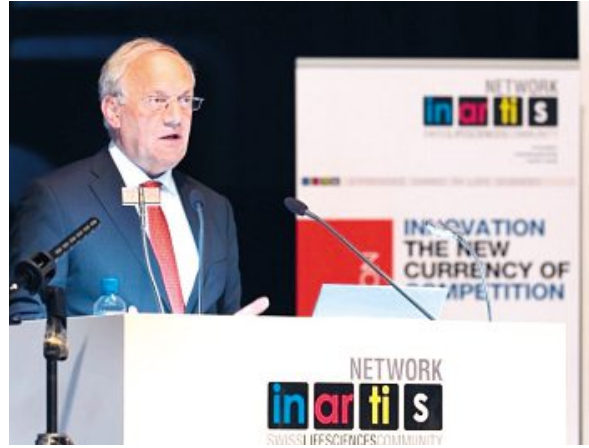

Fig. 2. Federal Council Johann N. SchneiderAmmann at the kick-off event of INARTIS NETWORK at EPFL on 28 March 2013.

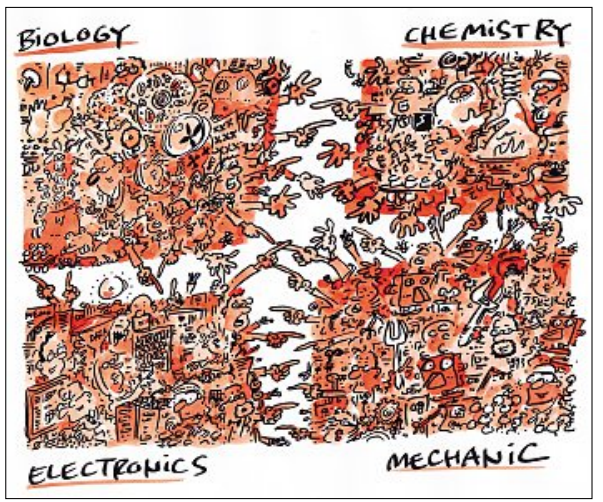

Fig. 3. The need for a transdisciplinary approach in the Life Science for 'Innovation Made in Switzerland' as seen by Pécub.

sectors involved: INARTIS NETWORK therefore focuses on a trans-disciplinary approach and fosters cross-industry R\&D collaborations. What this concretely means is the following:

Particular aspects of innovation in Life Sciences are the many scientific disciplines and businesses involved, all benefiting of rapid knowledge gain. For large companies with important $R \& D$ capacities and business connections, the 'thinking in silos' represents a major hurdle for innovation: those companies have access to the new knowledge; however they often struggle with over-specialisation and internal complexity. For most SMEs, the situation is different, as many CEOs explain to us: they are fully occupied with operational day-to-day tasks and all too often do not find the time to think about innovation. Also, they only have limited resources to hire scientists and certainly can't build up large R\&D capacities uniting all the different disciplines.

INARTIS NETWORK actively supports SMEs and also large companies to bridge those gaps by activating our extended network for setting up R\&D collaborations, events and workshops between industry and academia. We strongly rely on the most experienced people in those many fields: Senior Expert, including retired experts from industry and academia 
in a network that includes today over 1700 people. INARTIS NETWORK has a 'no wrong door policy': if your topic is related to Life Sciences we are certainly able to support you directly or redirect you to the right partner.

"For a SME, managing innovation is challenging", tells Marco Brini. He is the CEO of EnvEve SA, a Ticinese company successfully running Wireless Sensor Technology applications for environmental monitoring in several European countries (Fig. 4). "Inartis Network contacted me, offering support to get involved in a very strategic $R \& D$ project on ICTAgri (Information and Communication Technology in Agriculture). EnvEve has great expertise in this topic and we were working on more advanced solutions. However, we were lacking connections, time and also money for R\&D. After the first reaction of scepticism, I had the opportunity to assess the services provided by Inartis Network. Results - or lack of them! - are the only metrics used by an entrepreneur. I have to admit that the results were much above expectations. We now are a solid R\&D consortium with a robust business plan and soon ready to file our CTI-project application”. He underlines that "the support AGIRE (Innovation promotion from Canton Ticino) will give EnvEve for this project shows that also my canton helps entrepreneurs". Marco Brini concludes: "For me, such NTNs and cantonal support bringing together business and science from all over the country are

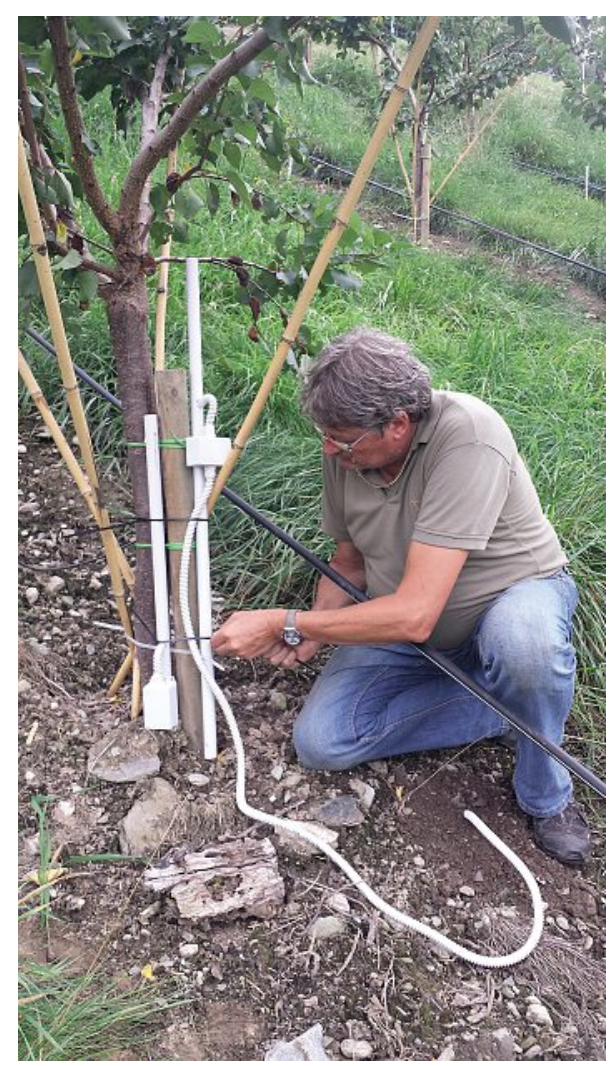

Fig. 4. Philippe Monney from the Agroscope Research Station in Conthey/VS setting up the EnvEve SA monitoring system in an experimental apricot orchard.

an important drop in the sea of innovation helping Switzerland to stay in the lead as a positive environment for innovative companies".

\section{Call to Action}

Innovation is at the heart of any business success. CTI, cantonal innovation promotion agencies and other public and private sector players provide support.

Want to turn scientific research into business results? Need for scientific input to stay ahead of the game? Just contact the National Thematic Network in the domain you want to move ahead: Inartis Network and the fellow NTNs look forward to supporting you (Fig. 5).

Received: September 22, 2014

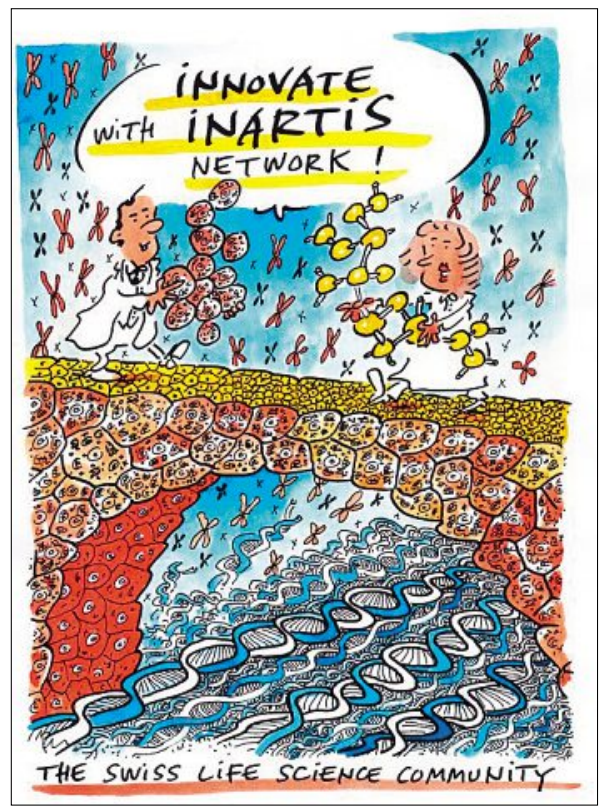

Fig. 5. Building bridges for Innovation as seen by Pécub. 